\title{
IMPLEMENTASI INTERNAL WIRELESS ROAMING MENGGUNAKAN MIKROTIK WIRELESS DISTRIBUTION SYSTEM (WDS) PADA STMIK LOMBOK
}

\author{
Falah Husni' ${ }^{1}$ Mohammad Taufan Asri Zaen²
}

Program Studi Teknik Informatika

Sekolah Tinggi Manajemen Informatika dan komputer (STMIK) Lombok

Jln. Basuki Rahmat No.105 Praya Lombok Tengah 83511

1 falahhusni17@gmail.com, ${ }^{2}$ opanzain@gmail.com

\begin{abstract}
Currently the hotspot network used by students in STMIK Lombok uses Basic Service Set topology (BSS), therefore different Service Set Identifier (SSID) in each Access Point (AP) causes the mobility and reliability of the hotspot network to decrease.

To overcome this problem can be applied hotspot system with Extended Service Set topology (ESS) that uses more than one AP and integrate all AP into a single wireless network using Internal Wireless Roaming so that client mobility is not disturbed when moving locations in the campus area without having to reconfigured.

The signal coverage test of roaming network that has been done in STMIK Lombok using Wireless Distribution System (WDS) has not reached all campus area but can be overcome by adding AP to increase coverage area. Roaming that runs between APs can work but requires more time in the process of moving.
\end{abstract}

Keywords: Hotspot, Basic Service Set (BSS), Service Set Identifier (SSID), Extended Service Set (ESS), Internal Wireless Roaming, Wireless Distribution System (WDS)

\begin{abstract}
Abstrak
Saat ini jaringan hotspot yang digunakan mahasiswa di STMIK Lombok menggunakan topologi Basic Service Set (BSS), karena itu Service Set Identifier (SSID) yang berbeda-beda di setiap Access Point (AP) menyebabkan mobilitas serta reliabilitas dari jaringan hotspot tersebut berkurang.

Untuk mengatasi hal tersebut bisa diterapkan sistem hotspot dengan topologi Extended Service Set (ESS) yang menggunakan lebih dari satu AP dan mengintegrasikan semua AP menjadi satu kesatuan jaringan wireless menggunakan Internal Wireless Roaming agar mobilitas klien tidak terganggu saat berpindahpindah lokasi di area kampus tanpa harus melakukan konfigurasi ulang.

Uji coba jangkauan sinyal dari jaringan roaming yang telah dilakukan di STMIK Lombok menggunakan Wireless Distribution System (WDS) belum menjangkau seluruh area kampus namun bisa diatasi dengan menambah AP untuk menambah coverage area. Roaming yang berjalan antar AP bisa berjalan namun membutuhkan lebih banyak waktu dalam proses perpindahan.
\end{abstract}

Kata kunci: Hotspot, Basic Service Set (BSS), Service Set Identifier (SSID), Extended Service Set (ESS), Internal Wireless Roaming, Wireless Distribution System (WDS),

\section{Pendahuluan}

Pembangunan hotspot menggunakan topologi BSS (Basic Service Set) menyebabkan client kurang efektif saat menggunakan fasilitas hotspot dan berpindah-pindah lokasi. Masalah yang muncul adalah user harus melakukan login ulang jika berpindah dari satu access point ke access point yang lain. Hal ini menyebabkan mobilitas serta reliabilitas dari jaringan hotspot tersebut berkurang.

Untuk mengatasi hal tersebut bisa diterapkan sistem hotspot dengan topologi extended service set (ESS) yang menggunakan lebih dari satu access point dan menjadikan access point-access point tersebut menjadi satu kesatuan jaringan, hal ini di harapkan 
menambah coverage area hotspot untuk mempermudah mahasiswa dalam mengakses internet di area kampus.

\section{Tinjauan Pustaka}

Sejati, dkk (2012) dalam penelitiannya tentang perancangan dan analisis external wireless roaming pada jaringan hotspot, dengan menerapkan topologi ESS yang memakai wireless roaming, jaringan hotspot yang dibangun memiliki reliabilitas yang lebih baik dibandingkan dengan jaringan hotspot yang menggunakan topologi BSS. jangkauan dari suatu jaringan hotspot dapat bertambah luas. Selain itu jaringan hotspot yang dibuat dapat menampung lebih banyak user

Penelitian Sofyan, dkk (2015) tentang analisis dan perancangan wireless roaming, Dalam hal stabilitas untuk jaringan hostpot yang menggunakan wireless roaming cukup stabil dilihat dari hasil pengujian bahwa clien dapat bergerak dan mendapatkan IP yang sama tanpa melakukan konfigurasi ulang dan jangkauan dari suatu jaringan hotspot dapat bertambah luas dan jumlah user- nya.

Prasetyo, dkk (2014) dalam penelitiannya tentang analisis dan optimalisasi jaringan nirkabel dengan minimalisasi roaming, roaming terdiri dari dua macam karakterisitik yaitu: (1) Seamless Roaming adalah kondisi di mana roaming terjadi pada saat transfer data sedang berjalan, dan roaming yang terjadi tidak mengakitbatkan transfer data yang sedang berlangsung terputus. (2) Nomadic Roaming adalah roaming yang terjadi saat tidak ada transfer data pada client.

Penelitian Subardono, dkk (2011) tentang analisis performa WDS, konfigurasi star dan mesh bisa dipakai untuk hotspot, dimana throughput yang dihasilkan pada konfigurasi star lebih besar dan waktu tundanya lebih kecil dibandingkan dengan konfigurasi mesh. Sehingga performa konfigurasi star lebih baik dibandingkan dengan mesh.

\section{Wireless Roaming}

Wireless roaming adalah keadaan dimana suatu mobile station dapat berpindah dari satu access point ke access point yang lain, dan masih dalam subnet yang sama tanpa harus melakukan koneksi ulang ke access point. Mobile station dapat menemukan access point yang memiliki sinyal terbaik, kemudian memutuskan kapan untuk berpindah ke access point yang lain. Semua proses tersebut membutuhkan waktu dalam pemilihan access point terbaik maupun konfigurasi IP address. Wireless roaming dapat membantu mobile station untuk mendapatkan alamat IP yang baru tanpa mempengaruhi koneksi. Pemindaian dan pengambilan keputusan adalah bagian dari proses roaming yang memungkinkan mobile station menemukan access point baru pada saluran yang cocok ketika pengguna berpindah tempat.

Dalam jaringan wireless, roaming antara dua jaringan terdiri dari internal roaming dan external roaming. Internal roaming terjadi jika mobile station berpindah ke jaringan lain melalui satu access point ke access point yang lain tetapi masih dalam satu home network. Sedangkan external roaming terjadi jika mobile station sudah berpindah antar provider jaringan yang digunakan.

\section{Mikrotik Wireless Distribution System}

WDS (Wireless Distribution System) adalah sistem yang memungkinkan interkoneksi antar access point. Sistem ini digunakan untuk memperluas jangkauan area wireless, dengan menggunakan beberapa perangkat access point yang menjadi satu kesatuan, tanpa membangun backbone jaringan. Syarat dalam membangun jaringan WDS adalah access point harus menggunakan Band, Frequency, dan SSID yang sama. Konsep WDS adalah dengan mengkonfigurasi access point dengan WDS, maka apabila user_laptop berpindah dari satu area access point ke area access point lainnya, maka user seakan-akan tetap berada di area yang sama.

\subsection{Wireless AP non-WDS}

Pada gambar 4.1 terlihat apabila user berpindah tempat dari area access point 1 ke area access point lain (access point 2 atau access point 3), maka user akan mengalami kehilangan koneksi beberapa saat dan harus melakukan login ulang sebelum terhubung ke access point yang baru.

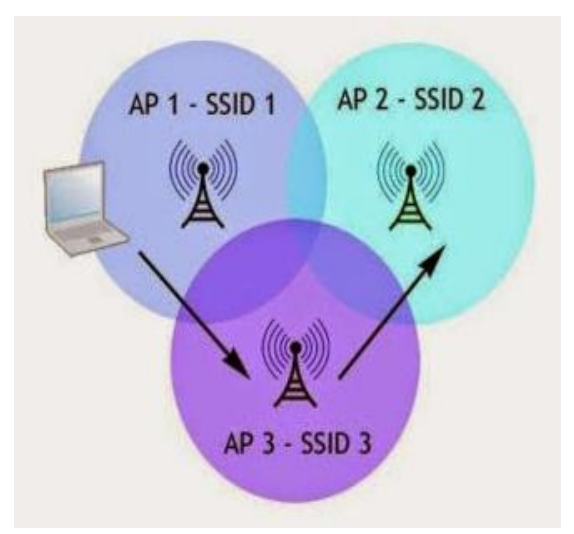

Gambar 4.1 Wireless access point non-WDS 


\subsection{Wireless AP dengan WDS}

Pada gambar 4.2 apabila user berpindah tempat dari area access point 1 ke area access point lain (access point 2/access point 3), maka user seakan-akan tetap berada di area yang sama tanpa perlu kehilangan koneksi dan user tidak perlu melakukan login ulang untuk dapat terkoneksi.

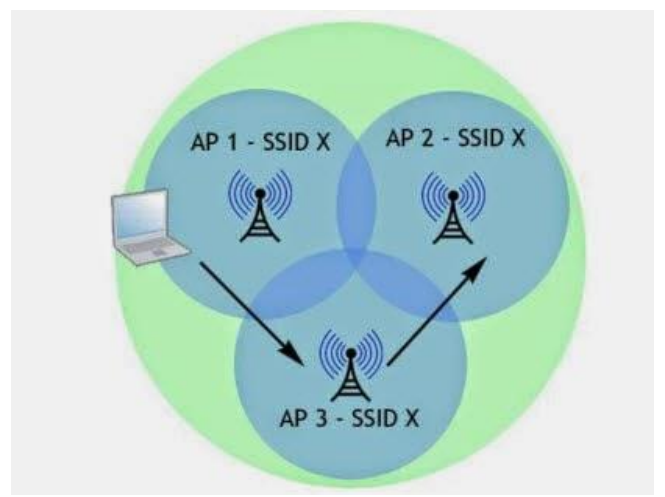

Gambar 4.2 Wireless access point dengan WDS

\section{Analisis Masalah dari Arsitektur Jaringan Saat ini}

\subsection{Topologi Jaringan}

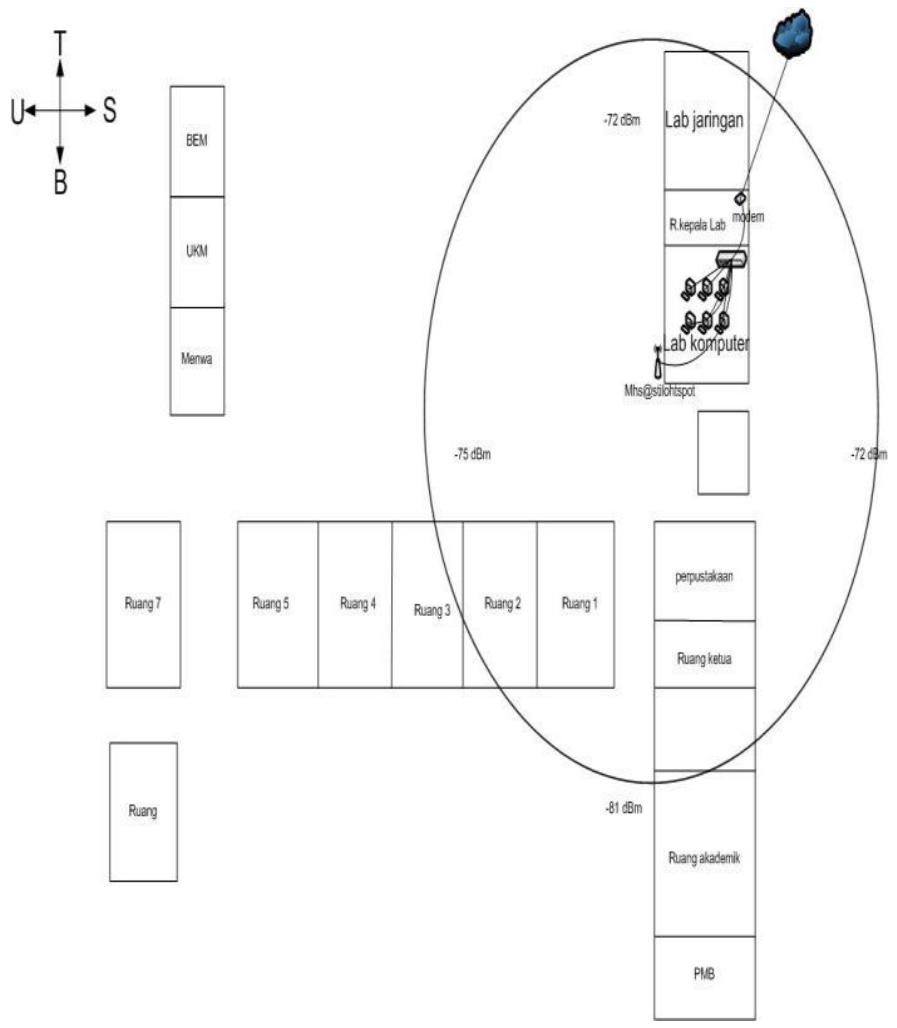

Gambar 5.1 Topologi Jaringan yang Berjalan

Bentuk jaringan nirkabel yang sedang berjalan di STMIK Lombok saat ini mengggunakan topologi basic service set (BSS) karena pada jaringan wireless STMIK lombok hanya menggunakan satu access point, Topologi jaringan ini tentu memiliki kekurang. Karena menggunakan hanya satu access point membuat jangkauan access point dan jumlah user yang bisa mengakses internet menjadi terbatas.

Jaringan komputernya masih menggunakan topologi basic service set (BSS) untuk jaringan wirelessnya, tentu saja penggunaan topologi ini tidak memadai untuk digunakan karena menggunakan satu access point. Penggunaan access point yang melayani kurang lebih 30 pengguna/clien dan daerah jangkauan sekitar 20-30 mater tidak akan bisa melayani mahasiswa yang jumlahnya 100 perhari.

\subsection{Analisis Performa Sistem}

Jaringan wifi yang tersedia untuk mahasiswa mengakses internet saat menggunakan satu access point yang di harapkan bisa menjangkau seluruh area kampus STMIK Lombok dan melayani kebutuhan semua mahasiswa mengakses internet. Hal ini tentu membuat jaringan yang sudah ada sekarang hanya terfokus di satu tempat yakni laboraturium komputer sehingga mahasiswa yang ingin mengakses internet harus mendekat ke ruangan laboraturium komputer hal ini mempengaruhi mobilitas mahasiswa yang ingin mengakses internet.

Selain itu karna menggunakan satu access point client/mahasiswa yang bisa di layani hanya sebagian dari mahasiswa. Karena penggunakan access point yang bisa melayani kurang lebih 50 pennguna/client dan daerah jangkauan sekitar 30-50 meter tidak bisa melayani jumlah mahasiswa yang membutuhkan akses internet.

\subsection{Topologi Jaringan yang di Usulkan}

Topologi jaringan nirkabel yang akan digunakan adalah topologi extended service set (ESS). Topologi ini mendukung penggunaan access point lebih dari dalam satu jaringan nirkabel.

Pemilihan perangkat jaringan yang digunakan, terdiri dari modem, routerbord, 3 wireless access point, switch dan menggunakan kaber UTP sebagai media transmisi untuk menghubungkan antar perangkat. Dan juga menggunakan OS mikrotik v5.16, dengan menggunakan fiture wireless distribution system yang ada pada mikrotik bisa melakukan proses roaming pada 3 access point yang akan digunakan. 


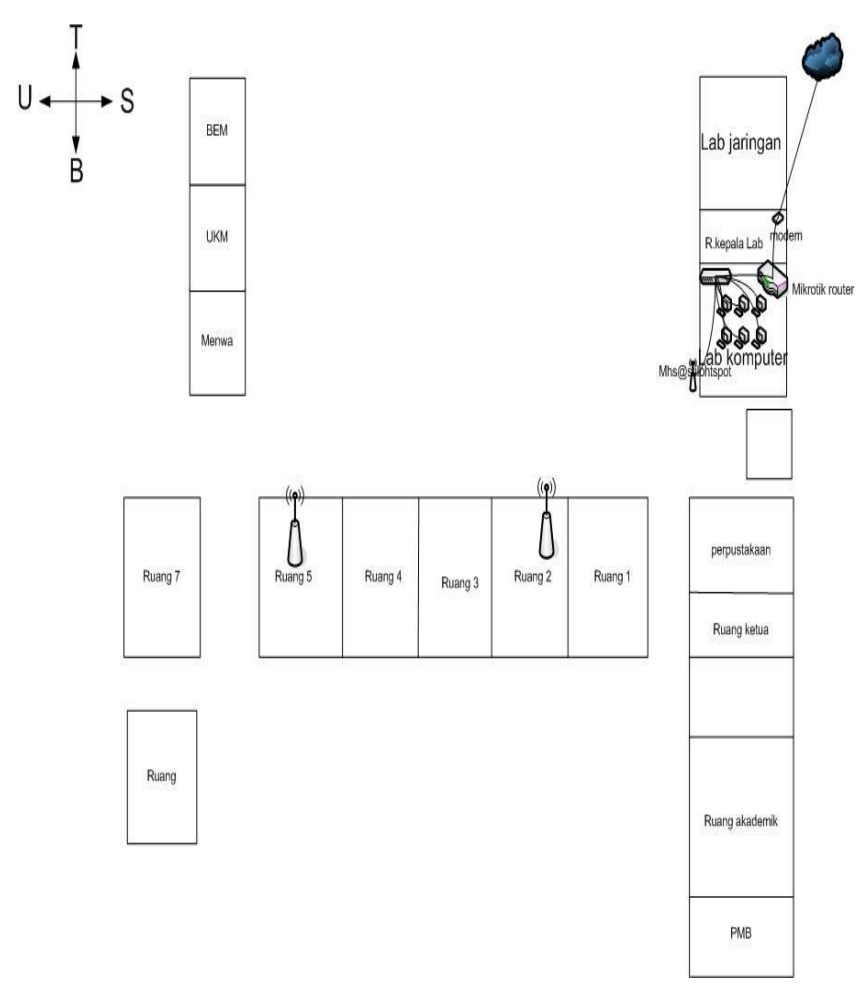

Gambar 5.2 Topologi Jaringan yang di Usulkan

Pembangunan jaringan wireless menggunakan topologi extended service set (ESS) dan menggunakan mikrotik wireless distribution system yang menyatukan ketiga access point dan menjadikan satu kesatuan jaringan yang luas. Access point yang di gunakan mempunyai band, frequensy dan SSID yang sama. Dan jarak antara ketiga access point adalah 40 mater.

Langkah-langkah pembangunan jaringan mulai dari perancangan, intalasi dan pengujian sistem. Dimana akan tercipta jaringan yang mengakomodasi kebutuhan user dalam mobilitas mahasiswa mengakses internet dan jangkauan hotspot yang meluas. Jadi, ketika mahasiswa sedang mengakses internet di jangkauan access point 1 kemudian bergerak menjauh dan masuk ke dalam jangkauan access point 2 secara otomatis mahasiswa tersebut terkoneksi internet melalui accces point 2 tanpa harus melakukan login ulang.

\section{Implementasi}

\subsection{Instalasi Perangkat}

Instalasi perangkat keras yang ditambahkan pada jaringan yang dikembangkan berupa penambahan pemasangan mikrotik,2 buah access point, 2 buah Switch, dengan menggunakan kabel sebagai media transmisi dan konektor RJ45 sebagai konektornya.
Access point yang ditambahkan diletakkan di dua titik yaitu di ruang 2 dan ruang 5, pemasangan access point tidak menggunakan kabel sebagai media transmisinya tapi menggunakan wireless (nirkabel)

Instalasi perangkat lunak yang di gunakan yaitu winbox untuk untuk melakukan remote ke server mikrotik kita dalam mode GUI (Graphical User Interface), untuk mengkonfigurasi mikrotik wireless distribution system pada mikrotik, dan inssider untuk uji coba jaringan sudah di bangun.

\subsection{Konfigurasi Wireless Distribution System}

Konfigurasi wireless distribution system (WDS) pada mikrotik di mulai dari pemberian nama interface, pemberian alamat IP address utuk mikrotik, pengaturan $A P$ bridge, dan pengaturan WDS yang di lakuakan agar pendistribusian sinyal dari access point pada perangkat mikrotik ke access point lainnya berjalan dengan baik. Sedangkan konfigurasi yang di lakukan pada perangkat access point yang berfungsi untuk menerima sinyal dari perangkat access point pada mikrotik di mulai pemberian ip address untuk access point, konfigurasi wireless setting, dan menghubungkan perangkat access point mikrotik dengan access point lainnya melalui $A P$ list.

\subsection{Cara Uji Coba Jangkauan Sinyal Hotspot}

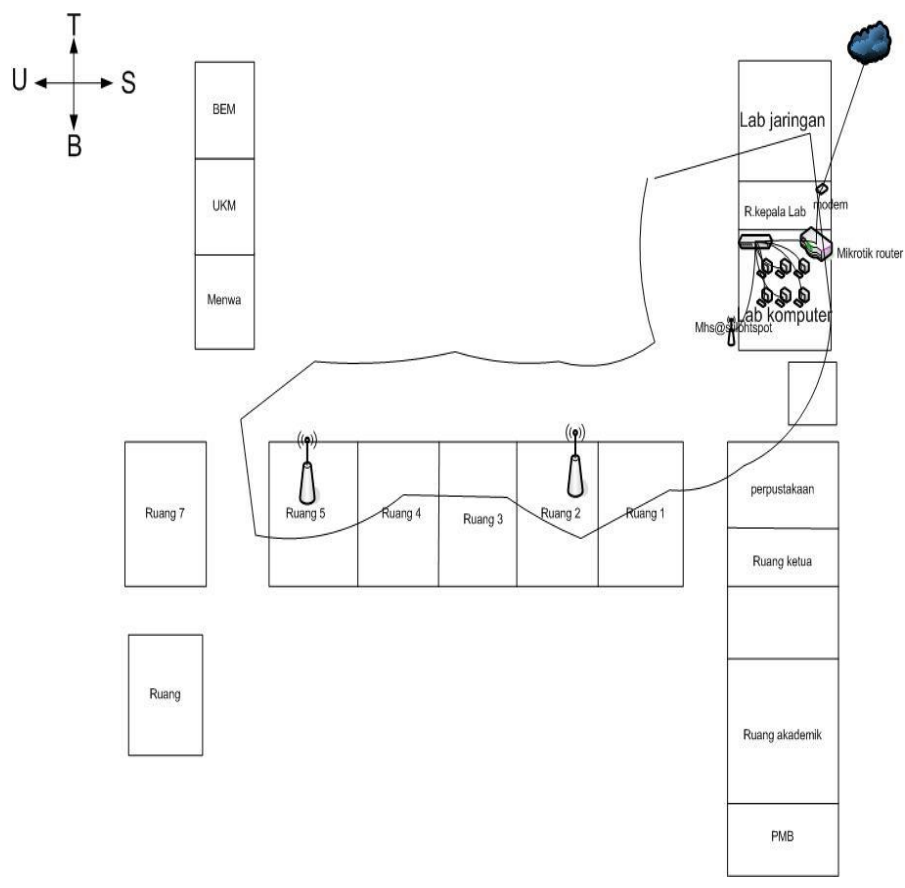

Gambar 6.1 Jangkauan Sinyal Roaming 
Cara uji coba jangkauan sinyal dari jaringan roaming yang di buat dengan cara menggunakan perangkat smartphone untuk mencari jangkauan sinyat hotspot yang mendapatkan sinyal sampai 3 baris. Ketika sudah mendapatkan jangkauan sinyal hotspot di beberapa titik maka akan di jadikan acuan gambaran jangkauan sinyal hotspot yang di buat.

\subsection{Cara Uji Coba Jaringan roaming}

Uji coba jaringan yang dirancang terlihat pada gambar 6.2. Uji cobanya dilakukan menggunakan satu buah perangkat leptop yang didalamnya sudah terinstal aplikasi inSSIDer.
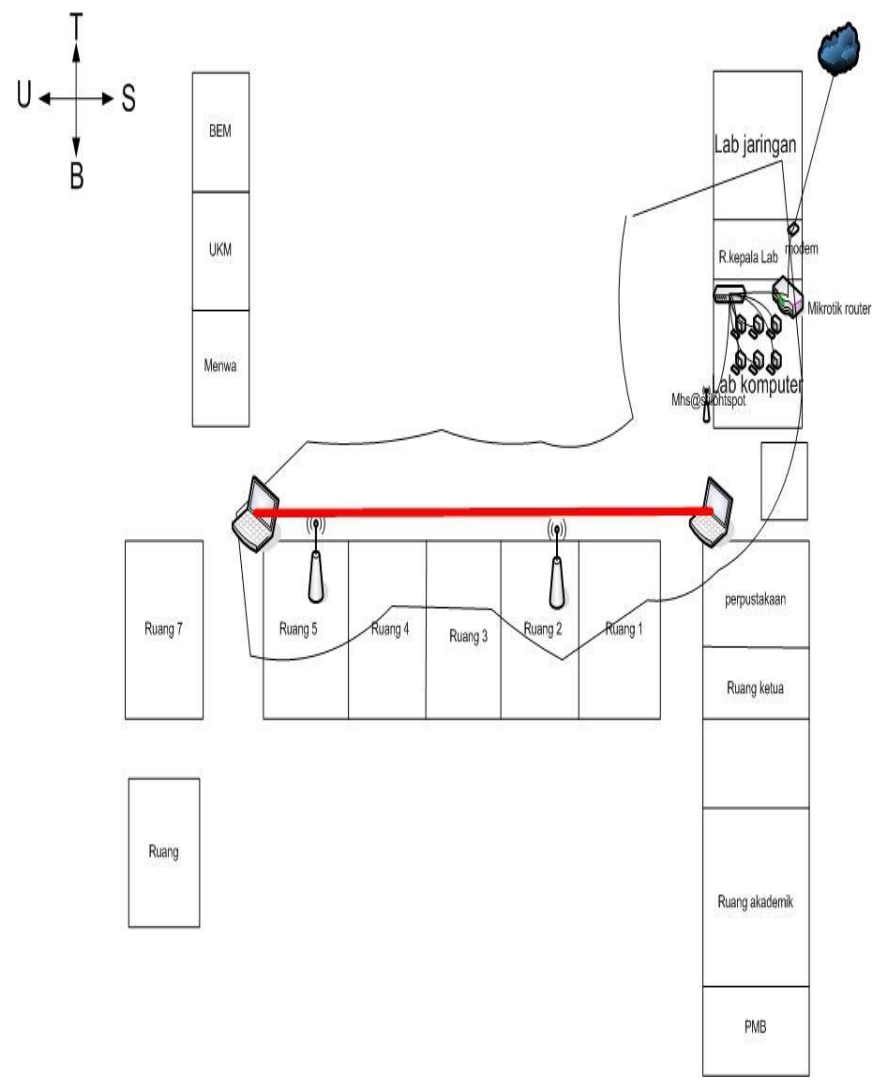

Gambar 6.2 Cara Uji Coba

Cara uji cobanya adalah dengan cara laptop yang sudah terinstal inSSIDer dibawa berjalan memonitor dari ruang 1 ke ruang 7 dengan aplikasi inSSIDer terbuka. Pada aplikasi inSSIDer akan terlihat kekuatan sinyal jaringan yang sudah dibuat dan roaming yang berjalan antara access point 1 dengan access point 2 berjalan dengan baik terlihat dari kekuatan sinyal pada aplikasi inSSIDer.

\section{Kesimpulan dan Saran}

\subsection{Kesimpulan}

Berdasarkan hasil perancangan dan pembangunan jaringan komputer yang telah diimplementasikan, dapat disimpulkan:

1. Pembangunan jaringan roaming menggunakan wireless distribution system (WDS) di kampus STMIK Lombok tidak bisa menjangkau seluruh area kampus, hal ini terlihat dari uji coba jangkauan sinyal dari jaringan roaming yang telah dilakukan.

2. Roaming yang berjalan antar access point pada jaringan hotspot yang dibangun bisa berjalan tapi membutuhkan lebih banyak waktu dalam proses perpindahan dari satu access point ke access point lainnya

3. Pembangunan jaringan roaming membutuhkan access point yang lebih banyak untuk menjangkau seluruh area kampus karena penempatan antar access point tidah boleh terlalu jauh agar roaming berjalan dengan baik

\subsection{Saran}

Berdasarkan perancangan dan pembangunan jaringan komputer yang telah dilakukan tentu memiliki kekurangan, untuk menutupi kekurangan tersebut di sarankan halhal sebagai berikut:

1. Di perlukan penambahan keamanan jaringan pada jaringan roaming yang telah di bangum

2. Jika di perlukan penambahan jangkauan hotspot yang lebih luas di sarankan agar menambahkan perangkat access point dan di konfigurasikan ke dalam jaringan roaming yang di buat.

3. Di butuhkan access point yang memiliki spesifikasi yang lebih tinggi agar jaringan roming berjalan dengan maksimal

\section{Daftar Pustaka}

Ahmad Jalaludin, Heru Sukoco (2012). "Analisis dan Evaluasi Jaringan Wifi sebagai Rekomendasi Rancangan Infrastruktur Wifi Studi Kasus Institut Pertanian Bogor (IPB)".

Alif Subardono, Lukito Edi Nugroho, Sujoko Sumaryono (2011). "Analisa Performa Wireless Distribution System Komfigurasi Star dan Mesh Untuk Hotspot Area." Jurnal Seminar Nasional Informatika 2011 (semnasIF 2011).

Antonius Windy Purwanto (2014) "Analisis Internal Wireless Roaming Pada Jaringan Hotspot." Skripsi Universitas Sanata Dharma Yogyakarta, Yogyakarta. 
Anugrah Novanda Setyawan (2015). “Efek Roaming Internal Wireless LAN Pada Unjuk Kerja TCP." Skripsi Universitas Sanata Dharma Yogyakarta, Yogyakarta.

Audi Eka Prasetyo, Marco Stefanus, Admiral Wiem, Antonius Herusutopo. (2014). "Analisa dan Optimalisasi Jaringan Nirkabel dengan Minimalisasi Roaming di Binus Square." Jurnal Comtech Vol.5.

Fra Arsandy Kusuma Sejati, Indrastanti Ratna Widiasari, Theophilus Wellem. (2012). "Perbandingan dan Analisis External Wireless Roaming Pada Jaringan Hotspot Menggunakan Dua Jaringan Mobile Broadband." Jurnal Seminar Nasional Teknologi Informasi \& Komunikasi Terapan 2012 (Semantik 2012), Semarang.

Rozak, Abdul, and Ahmad Susan Pardiansyah. "Perancangan Jaringan Virtual Metametarouter." Jurnal Manajemen Informatika dan Sistem Informasi 1.1 (2018): 17-23.
Indra Ramadhani (2014) "Analisis dan Optimalisasi Cakupan Wireless Access Point 801.11 Studi Kasus STMIK AMIKOM." Skripsi STMIK AMIKOM Yogyakarta, Yogyakarta.

Kartini, Willy Adiansyah (2014) “ Membangun Jaringan Nirkabel (Hotspot Area) dan Menejemen Hotspot dengan "Antamedia Hotspot Menejer" sebagai Sarana Komersial Berbasis Wifi." Jurnal Ilmu Komputer Volume 10.

Kalaena, Lalu Supriadi, and Wire Bagye. "Implementasi Network Attached Storage (NAS) Menggunakan Freenas Pada STMIK Lombok." Jurnal Manajemen Informatika dan Sistem Informasi 1.1 (2018): 6-10.

Muammad Sofyan, Leon Andretti Abdillah dan Hadi Syahputra. (2015). "Analisis dan Perancangan wireless roaming (Studi Kasus 